\title{
Monetized environmental assessment of interior thermal insulation
}

\author{
Jan Fort ${ }^{1}{ }^{1 *}$, Jiř $^{\prime}$ Maděra $^{1}$ and Robert Černý $^{1}$ \\ ${ }^{1}$ Department of Materials Engineering and Chemistry, Faculty of Civil Engineering, Czech Technical \\ University in Prague, Thákurova 7, Prague 6, 166 29, Czech Republic
}

\begin{abstract}
Excessive production of carbon dioxide is viewed as one of the most threat to the current generation. While the industry and transportation sector significantly improve energy efficiency and more actions are awaited, the building sector still lacking similar progress. European member states committed a decrease in produced carbon emissions which emphasis energy retrofitting of current obsolete building stock. The complex assessment of used applied materials poses an important task and searching for an advanced approach is still a big challenge. On this account, the performed study contemplates the monetarization of all negative environmental externalities to support method towards acceptance of solution with long-term perspectives. Considering responsible attitude to environmental issues accompanied by whole service life of used materials. Obtained results revealed environmental costs of mineral wool production as a supporting tool for complex building retrofit assessment.
\end{abstract}

\section{Introduction}

The outdated and obsolete building envelopes are viewed as a limiting factor for energy efficiency in the building sector. Moreover, the building sector consumes about $40 \%$ of total energy production in Europe Union [1]. This undisputable fact significantly contributes to global climate change by excessive production of related carbon emissions. In order to reach ambitious carbon reduction target, set to decreased carbon dioxide production about $80 \%$ till 2050, a substantial action is needed. To meet those goals, from 2021 all new buildings in EU must fulfil nearly Zero Energy Building energy consumption criteria (NZEB) [2]. However, low energy consumption of new buildings cannot significantly affect the energy efficiency of the whole sector due to a limited share of new constructions. The energy conservation of existing buildings poses an essential task for policymakers in order to perform retrofit interventions and improve the thermal stability of buildings [3]. The crucial role in the energy efficiency of buildings is played by characteristics of its envelope. From this point of view, the utilisation of various insulation materials can provide enormous improvements and represents a prospective way to meet with NZEB regulations. Notwithstanding, a number of available insulation materials on the market is vast, and a proper assessment for optimal selection is complicated and still open challenge. While in the recent past, the consideration of the thermal performance of such materials was highlighted as the most critical parameter, the current practice is aimed at a more robust assessment. This fact was further supported by findings of Asrubali et al. [4] or Fořt et al. [5] who concluded, that environmental assessment of insulation materials production needs to be linked with possible energy saving during the whole service life regarding the overall benefit of retrofit strategy. In other words, application of high-

${ }^{*}$ Corresponding author: jan.fort@fssv.cvut.cz 
performance insulation material is beneficial not only from yearly energy cost savings but also from an environmental point of view, because a significant share of consumed energy is dedicated to the maintenance of interior thermal comfort. In the study of Dewulf et al. [6] was concluded that production of building materials needed for construction consist only $15-20 \%$ environmental load compared to service phase of building in 50 years lifespan. The identification of cost-optimal level for retrofits poses another critical task for decisionmakers [7, 8]. Usually, the employed assessment based on the comparison of initial and maintenance costs does not comply with sustainable principles and in the sense of circular economy [5, 6]. Since the outputs from LCA assessment were called as negative externalities of human activity, the integration of several midpoint or endpoint indicators into the coherent and monetarized one. Such an approach can promote adoption of more viable solution from the long-term perspectives without underestimation of important flows [3].

In this study, a complex economic assessment of mineral wool was done with included monetarized environmental midpoint indicators provided by life cycle assessment analysis. Such obtained results can significantly improve the quality of presented outputs and promote more responsible decision-making process.

\section{Materials and methods}

The framework of this study is based on three subsections, the determination of Life Cycle Inventory (LCI), Life Cycle Impact Assessment (LCIA) and Damage Cost Assessment (DCA).

The LCIA was carried out on the basis of standard methodology given in EN 15804. The data were incorporated into LCA modelling software SimaPro equipped by the EcoInvent v.3.2 life cycle inventory database.

\subsection{Goal and scope}

The main aim of this study is the evaluation of the environmental impact of mineral wool produced in the Czech Republic to provide data for monetization of particular impact categories.

\subsection{Studied material and functional unit}

A mineral wool is one of the most used insulation materials which can serve also as a fire protection or noise insulation thanks to its beneficial properties. A production of this material from the basalt rocks or slag originated during steel manufacturing can be divided to several stages: melting, fiberizing, polymerization, cooling and finishing. However, energy demanding production of mineral wool present, especially a high temperature treatment of raw materials is associated with a significant environmental burden and costs.

The chosen functional unit for monetized environmental assessment was $1 \mathrm{~m}^{3}$ of final product having the bulk density about $30 \mathrm{~kg} / \mathrm{m}^{3}$. The thermal resistance about of 2.65 $\mathrm{Km}^{2} \mathrm{~W}^{-1}$ was determined in compliance with EN 12162. For the comparison, EPS insulation board with thermal resistance of $2.60 \mathrm{Km}^{2} \mathrm{~W}^{-1}$ was used.

\subsection{Boundary conditions}

The cradle-to-gate boundary conditions were used as is illustrated in Fig. 1, and impacts connected to the extraction of raw materials, transportation and installation of materials 
were considered. Processes involved in the manufacturing of mineral wool were taken into account. Other life cycle stages i.e. use stage and end of life treatment were neglected within this study in order to access a more detailed insight into material processing. All processes involved in materials production from raw materials to manufacturing of readyto-use material were considered. Indirect emissions related to the material processing were calculated on the basis of the Czech Republic energy mix with the dominant share of fossil fuels power plants $(57.4 \%$ ), nuclear power plants (about $35 \%$ ) and only minor share of renewable sources (up to $7.6 \%$ ).

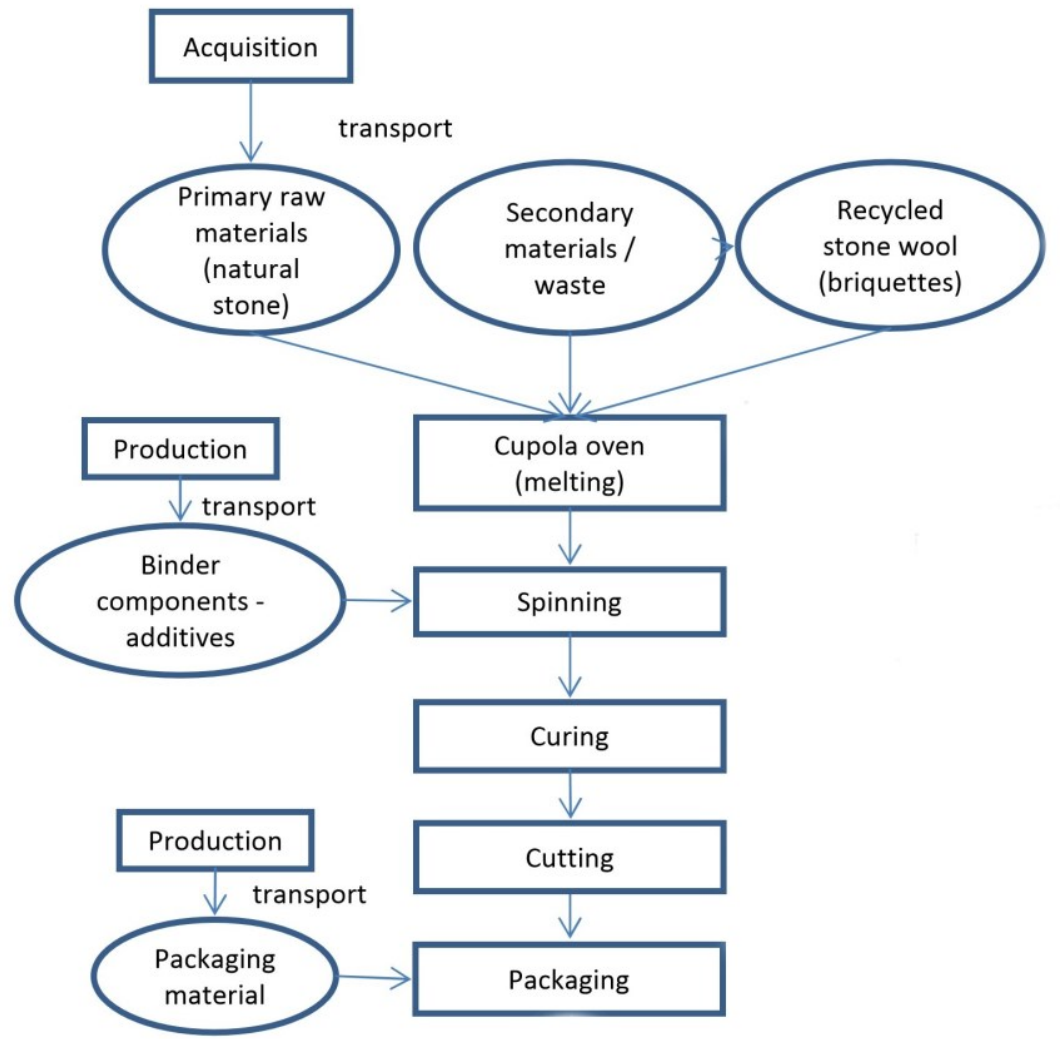

Fig. 1. Boundaries of LCA

\subsection{Impact assessment}

The main aim of the LCIA is a quantification of the negative environmental impacts of the described system within listed boundary conditions. As was mentioned above, the cradle to gate approach was used, and according to CML 2012 method the following mid-point indicators were calculated: global warming, ozone depletion, acidification of soil and water, eutrophication, photochemical ozone creation, abiotic resources depletion (elements) and fossil fuels depletion. 


\subsection{DCA assessment}

DCA calculate in detail how emissions, pollutants or use of resources causes damage to the environment to access a monetary value of such negative externalities. The demand depends on people's disposition to pay for environmental quality which can also be described as a willingness to pay. The costs imposed on the industries reflect the willingness of society to pay for avoidance of health or environmental problems in the long-term period. Namely, costs method can provide an overview how emissions of air pollutants disperse in the atmosphere, affect the agriculture and public health which leads to welfare losses in terms of additional costs, loss of income or comfort. The monetary valuation of such impacts uses different methods and data, appropriate to the type of impact. It includes market data and data from scientific literature to value pain or loss of life expectancy, based on revealed or stated willingness to pay. Table 2 provides an estimation of the monetary value for each environmental indicator that can be monetized. Listed values are based on the approach used by Debacker et al. [9].

Table 1. Monetary values for LCA indicators

\begin{tabular}{|l|c|c|}
\hline Environmental indicator & Unit & $\boldsymbol{\epsilon} / \mathbf{u n i t}$ \\
\hline Global warming & $\mathrm{kg} \mathrm{CO}_{2}$ eq & 0.1 \\
\hline Ozone depletion & $\mathrm{kg} \mathrm{CFC}^{-11} \mathrm{eq}$ & 100 \\
\hline Acidification & $\mathrm{kg} \mathrm{SO}_{2} \mathrm{eq}$ & 0.88 \\
\hline Eutrophication & $\mathrm{kg}\left(\mathrm{PO}^{3-}\right)^{3-} \mathrm{eq}$ & 60 \\
\hline Photochemical ozone creation & $\mathrm{kg}$ etheen eq & 6.6 \\
\hline Depletion of elements & $\mathrm{kg} \mathrm{Sb} \mathrm{eq}$ & 6.23 \\
\hline Depletion of fossil fuels & MJ, net caloric value & 0.0065 \\
\hline
\end{tabular}

\section{Results and discussion}

The obtained results from the LCIA analysis given in Table 2 were further used for monetisation of related environmental impacts (see Table 3). Such calculated environmental costs can be compared with possible consequent financial costs. Looking at the data, significant environmental impacts for mineral wool production can be assigned to the high energy demands related to a high-temperature treatment. However, obtained results seem to be similar compared to the production of other insulation materials widely applied in building practice, and only minor changes can be distinguished. Provided results are beneficial not only due to possible single score comparison and thus good basis for decision-making but also for the understanding of negative externalities which are usually underestimated. 
Table 2. Comparison of LCIA results of mineral wool and EPS production

\begin{tabular}{|l|c|c|c|}
\hline Environmental indicator & Unit & Mineral wool & EPS [10] \\
\hline Global warming & $\mathrm{kg} \mathrm{CO}_{2} \mathrm{eq}$ & 3.1 & 5.8 \\
\hline Ozone depletion & $\mathrm{kg} \mathrm{CFC}^{-11} \mathrm{eq}$ & $4.39 \mathrm{E}-08$ & $4.3 \mathrm{E}-08$ \\
\hline Acidification & $\mathrm{kg} \mathrm{SO}_{2} \mathrm{eq}$ & 0.00665 & 0.0077 \\
\hline Eutophication & $\mathrm{kg} \mathrm{(PO4})^{3-} \mathrm{eq}$ & 0.000796 & 0.0014 \\
\hline Photochemic ozone creation & $\mathrm{kg}$ etheen eq & 0.000372 & 0.0081 \\
\hline Depletion of elements & $\mathrm{kg} \mathrm{Sb}$ eq & $2.54 \mathrm{E}-07$ & $2.40 \mathrm{E}-06$ \\
\hline Depletion of fossil fuels & MJ, net caloric value & 13.85 & 170 \\
\hline
\end{tabular}

The monetised environmental impact of mineral wool production was clearly compared in Table 3 where a significantly higher value in euros was obtained for EPS board production with similar functional parameters. Namely, the monetized environmental externalities for EPS board was almost 4 times higher compared to mineral wool. The main difference is associated with overall higher energy consumption of EPS manufacturing process. Here the composition of energy production based mainly on fossil fuel combustion substantially affected the calculated values.

Table 3. Calculated environmental costs of mineral wool and EPS production

\begin{tabular}{|l|c|c|c|}
\hline Environmental indicator & Unit & Mineral wool & EPS \\
\hline Global warming & $\mathrm{kg} \mathrm{CO}_{2}$ eq & $3.10 \mathrm{E}-01$ & $5.80 \mathrm{E}-01$ \\
\hline Ozone depletion & $\mathrm{kg} \mathrm{CFC}^{-11}$ eq & $4.39 \mathrm{E}-06$ & $4.30 \mathrm{E}-06$ \\
\hline Acidification & $\mathrm{kg} \mathrm{SO}_{2}$ eq & $5.85 \mathrm{E}-03$ & $6.78 \mathrm{E}-03$ \\
\hline Eutophication & $\mathrm{kg} \mathrm{(PO} 4)^{3-} \mathrm{eq}$ & $4.78 \mathrm{E}-02$ & $8.40 \mathrm{E}-02$ \\
\hline Photochemic ozone creation & $\mathrm{kg}$ etheen eq & $2.46 \mathrm{E}-03$ & $5.35 \mathrm{E}-02$ \\
\hline Depletion of elements & $\mathrm{kg} \mathrm{Sb} \mathrm{eq}$ & $1.58 \mathrm{E}-06$ & $1.50 \mathrm{E}-05$ \\
\hline Depletion of fossil fuels & MJ, net caloric value & $9.00 \mathrm{E}-02$ & $1.11 \mathrm{E}+00$ \\
\hline Total & $\boldsymbol{\epsilon}$ & $\mathbf{0 . 4 5 6 1}$ & $\mathbf{1 . 8 2 9 3}$ \\
\hline
\end{tabular}

Since the viability of the reconstruction works is extensively studied, the economic factors were revealed as one of the most important ones. The average market price of mineral wool is usually higher compared to EPS insulation and prevents its wider application despite the more favourable moisture transport properties or fire resistance. The integrated single score value can be viewed as a practical decision-supporting tool for stakeholders.

The inclusion of environmental costs for estimation of total costs (see Table 4) allows a more consistent comparison of these two competitive materials and outline better viability for mineral wool.

Table 4. Total costs of mineral wool and EPS per $\mathrm{m}^{3}$

\begin{tabular}{|l|c|c|}
\hline & Mineral wool $(\boldsymbol{\epsilon})$ & EPS $(\boldsymbol{\epsilon})$ \\
\hline Market price per $\mathrm{m}^{2}$ & 8.17 & 6.89 \\
\hline Environmental costs per $\mathrm{m}^{2}$ & 0.46 & 1.83 \\
\hline Total costs per $\mathbf{m}^{2}$ & $\mathbf{8 . 6 3}$ & $\mathbf{8 . 7 2}$ \\
\hline
\end{tabular}




\section{Conclusions}

The submitted paper contemplates the monetization of environmental impacts of mineral wool insulation as an effective single score value for a precise interpretation of obtained results. Within the evaluation, the monetized environmental impacts were coupled together with a real market price to outline total costs of material as complex score promoting the principles of sustainable development. Notwithstanding, the application of such approach is still problematic due to a poor environment responsibility of material manufacturers and fragmented literature background. Despite those issues, the multidisciplinary approach integrating environmental and economic assessment is needed to overcome apparent barriers and provide a complex decision supporting tool for building retrofits. In light of these findings, the effective retrofit strategy must be related to the mitigation of the negative consequences of human activity from the broader perspective to deliver a favourable solution.

This research has been supported by the Ministry of Culture of the Czech Republic, under project DG16P02H046.

\section{References}

1. International Energy Agency, $\mathrm{CO} 2$ Emissions from Fuel CombustionParis, France, 2008, pp. 512.

2. R.P.N. Talang, S. Sirivithayapakorn, J. Clean. Prod. 197, 1508 (2018).

3. F. Asrubali, I. Ballarini, V. Corrado, L. Evangelisti, G., Graziechi, C., Guattari, Build. Environ. 147, 461 (2019)

4. G. de la Hera, I. Munoz-Díaz, E. Cifrian, R. Vitorica, O.G.S. Martin, J.R. Viguri, Waste Biomass Valor. 8, 1505 (2017)

5. J. For̆t, P. Beran, Z. Pavlík, R. Černý, J. Clean. Prod. 202, 871 (2018)

6. J. Dewulf, G. Van der Vorst, N. Versele, A. Janssens, H.Van Langenhove, Resour. Conserv. Recy 53, 231 (2009)

7. J. L. Sohn, P. P. Kalbar, G. T. Banta, M. Birkved, J. Clean. Prod. 162, 449-457 (2017)

8. F. Taillandier, L. Mora, D: Breysse, Build. Environ. 109, 121 (2016)

9. W. Debacker, K. Allacker, C. Spirinckx, T. Geerken, F. De Troyer, J. Clean. Prod. 57, 188 (2017)

10. EPD Isover EPS 100, General report on Isover LCA Cesky Brod, Paris, France: Isover, 2016 